\title{
ANALISA KELAYAKAN INVESTASI USAHA PEMBENIHAN IKAN DI BALAI BENIH IKAN (BBI) LOKAL KABUPATEN KUBU RAYA
}

\author{
M. Taufik*, Ani Muani**, Radian** \\ *Mahasiswa MMA Fakultas Pertanian Universitas Tanjungpura Pontianak \\ ** Staf Pengajar Fakultas Pertanian Universitas Tanjungpura Pontianak
}

\begin{abstract}
"Business Investment Feasibility Analysis of Fish Hatchery in Local Fish Breeding Center (BBI) of Kubu Raya Regency".

Development of freshwater fish farming in Kubu Raya regency is highly depends on the availability of qualified fish seed, since it is the input for the fish farmers. In relation with the provision of qualified fish seeds, the local government through the Department of Fisheries and Marine has build a local fish breeding center (BBI) in Kubu Raya regencyas aunit that produces qulified fish seed. It aimstomeet the needs of fish seed in Kubu Raya, so that may contribute toan increase in local revenue (PAD).
\end{abstract}

The objective of this researchare: to analyze the demand of the type and the amount of fish seeds in Kubu Raya regency, how muchfish seeds produced in accordance with the capacity of facilities and infrastructure in BBI;to analyze the feasibility of a fish hatchery business investments, how much profit sobtained compared to costs incurred by local governments which can contribute to the increased of PAD; and to analyze the sensitivity of investment feasibility fish hatchery operations in the event of changes in the factors that may affect the benefits and costs .

This research was conducted by using a qualitative descriptive and Microsoft Excel program to assess the feasibility of business investment in fish hatchery local BBI of Kubu Raya regency. Based on the analysis of fish seed demand in Kubu Raya regency, namely 4.084 million seed catfish, 2.776 million tilapia and 808.640 carp, while in West Kalimantan fish seed requirement are 36,106,560 catfish, 20,913,680 tilapia and $20,482,880$ carp. Fish seed production capacity in local BBI of Kubu Raya Regency is 2.288 million seed catfish, 1.884 million seed tilapia and 1.055 million seedcarp.

The results of the feasibility analysis of business investment in fish hatchery local $\mathrm{BBI}$ of Kubu Raya regency shows NPV $=4,698,084$, Net B/C 1.19, IRR $16.17 \%$ and PBP 5 years 1 month with10 years project duration, and thus the investment business in fish hatchery local BBI of Kubu Raya regencyis feasible. Sensitivity analysis shows that if there is an increase of production costs (feed, fertilizer, lime and drugs) of $7.62 \%$, the value of profitability NPV $=4,575,511$, net B/C 1.101, IRR 16,11\%, and PBP 5 years 6 months. In conclusion, business investment of fish hatcheries in local BBI Kubu Raya regency is feasible.

Keywords : Demand seeds, investment feasibility, fish hatchery, Local BBI .

\section{PENDAHULUAN}

Pembangunan BBI lokal sebagai penghasil induk unggul untuk keperluan Unit Pembenihan Rakyat (UPR) dan produksi benih unggul sebagai input pembudidaya ikan di wilayah kerjanya, BBI lokal juga bertugas untuk melakukan pembinaan, pemantauan, penerapan teknik pembenihan ikan, distribusi benih ikan, pengendalian mutu benih ikan, pelestarian sumberdaya ikan dan lingkungan. Disamping itu $\mathrm{BBI}$ lokal juga dituntut memberi kontribusi kepada Pendapatan Asli Daerah (PAD). Mudjiutami, (2011) permintaan kebutuhan benih ikan di Kalimanatan Barat umumnya jenis benih ikan, yaitu; mas, lele, nila dan patin. Selama ini permintaan benih tersebut dipenuhi berasal dari UPR 
dan BBI lokal Kabupaten/Kota yang ada di Kalimantan Barat, tetapi belum mencukupi kebutuhan benih yang dibutuhkan pembudidaya ikan didaerah oleh karena itu sebagian besar benih ikan berasal dari Pulau Jawa. Dengan demikian diharapkan dengan dibangunnya BBI lokal Kabupaten Kubu Raya dengan melakukan usaha pembenihan ikan dapat memenuhi permintaan benih pembudidaya ikan di daerah tersebut dan diharapkan dapat memberi kontribusi kepada PAD.

Usaha pembenihan ikan untuk memenuhi kebutuhan benih pembudidaya ikan di Kalimantan Barat umumnya dan Kabupaten Kubu Raya khususnya, sebagai penyumbang PAD merupakan proyek pemerintah yang memerlukan investasi dana yang cukup besar karena menyangkut pengeluaran modal misalnya tanah, mesin, bangunan kolam, sarana produksi dan pengembangan, untuk itu analisis kelayakan investasi usaha pembenihan ikan di BBI lokal Kabupaten Kubu Raya memilki peranan yang penting untuk mengetahui apakah manfaatnya lebih besar dari biaya yang dikeluarkan oleh pemerintah daerah Kabupaten Kubu Raya pada masa yang akan datang.

\section{METODE PENELITIAN}

Metode yang digunakan dalam penelitian Analisis kelayakan investasi usaha pembenihan ikan di BBI lokal Kabupeten Kubu Raya adalah metode deskriptif dan kualitatif. Metode deskriptif tidak hanya menggambarkan saja tetapi melakukan pengukuran yang cermat terhadap fenomena sosial tertentu. Ciri-ciri penelitian deskiptif pada pemecahan masalah-masalah yang ada pada masa sekarang secara actual, data dikumpulkan, disusun, dijelaskan dan dianalisis. (Trenggonowati, 2009). Metode deskripsi menggambarkan terhadap kegiatan usaha pembenihan ikan. Metode kuanlitatif, yaitu perhitungan dengan komputerisasi program microsoft excel dan disajikan dalam bentuk tabulasi yang digunakan untuk mengklasifikasi data yang ada serta mempermudah dalam analisis finansial untuk mengetahui kelayakan investasi usaha pembenihan ikan di BBI lokal Kabupaten Kubu Raya.

\section{PENGOLAHAN DAN ANALISIS DATA}

Analisis data meliputi analisis penentuan kebutuhan benih di Kabupaten Kubu Raya dan Kalimantan Barat umumnya dan analisis kelayakan investasi usaha pembenihan ikan di BBI lokal Kabupaten Kubu Raya dengan analisis finansial.

\section{Analisis Kebutuhan Benih Ikan}

Menentukan kebutuhan benih ikan di Kabupaten Kubu Raya dihitung berdasarkan hasil produksi perikanan budidaya pertahunnya (Data Dinas Kelautan dan Perikanan Kabupaten Kubu Raya, 2012) dan juga rencana pengembangan perikanan budidaya air tawar yang akan dilakukan. Kebutuhan benih ikan per tahun dapat dihitung dengan persamaan:

\section{Kebutuhan Benih = Produksi Budidaya Ikan x Bobot Rata-Rata Hasil Panen}

Jika dalam proses budidaya rata-rata jumlah bibit yang mati sebesar $50 \%$ (yang hidup $50 \%$ ), maka jumlah kebutuhan benih riel adalah:

\section{Kebutuhan Benih Riel = Populasi Ikan Panen x Tingkat Kematian Benih}

Data juga dapat diperoleh dari proyeksi kebutuhan benih ikan air tawar Dinas Perikanan dan Kelautan Kabupaten Kubu Raya dan Dinas Perikanan dan Kelautan Kabupaten Kubu Raya Propinsi Kalimanatan Barat.

\section{Analisis Kelayakan Investasi Usaha Pembenihan Ikan}


Data kuantitatif meliputi biaya-biaya yang dikeluarkan untuk melakukan usaha pembenihan ikan mencakup biaya investasi dan biaya operasional serta penerimaan dari hasil penjualan benih ikan. Penilaian kelayakan investasi usaha pembenihan ikan, Menurut Cholik, dkk (1999) kriteria yang umum digunakan adalah: 1) NPV; 2) Net Benefit/Cost; 3) IRR); 4) PBP. Analisa sensivitas untuk menganalisa apabila terjadi perubahan factor produksi yang mempengaruhi biaya dan penerimaan.

\section{Net Present Value (NPV)}

Sulisyanto (2010) menyatakan bahwa metode NPV merupakan metode yang dilakukan dengan cara membandingkan nilai sekarang dari aliran kas masuk bersih (proceeds) dengan nilai sekarang dari biaya pengeluaran suatu investasi (Out lay). NPV menunjukan kelebihan manfaat dibandingkan dengan biaya. Menurut Choliq, duke (1999) NPV menggunakan rumus sebagai berikut:

$$
N P V=\sum_{t=0}^{n} \frac{B_{t}-C_{t}}{(1+i)^{t}}
$$

\section{Keterangan :}

$\mathrm{Bt}=$ Benefit pada tahun ke- $\mathrm{t}$

$\mathrm{Ct}=$ Biaya pada tahun ke-t

DF = Discount Factor

$\mathrm{i} \quad=$ Lamanya waktu/umur investasi

$\mathrm{n} \quad$ = Tingkat bunga yang berlaku

Pengambilan keputusan investasi usaha pembenihan ikan di BBI lokal Kabupaten Kubu Raya yang diusulkan dinyatakan layak jika NPV lebih besar dari nol atau bernilai positif. Sebaliknya, jika NPV suatu NPV lebih kecil dari nol atau bernilai negative maka investasi pembenihan ikan air tawar di BBI lokal di Kabupaten Kubu Raya tersebut dinyatakan tidak layak.

\section{Net Benefit/Cost (Net B/C)}

Net B/C merupakan perbandingan antara jumlah NPV positif dengan jumlah NPV negatif. Net B/C menunjukan gambaran berapa kali lipat benefit akan diperoleh dari cost yang dikeluarkan, artinya setiap nilai sekarang dari pengeluaran sebesar 1 rupiah akan memberikan penerimaan sebesar Rp. 1 dengan jangka waktu pengembalian modal selama umur investasi usaha pembenihan ikan. Cara perhitungan Net B/C sebagai berikut:

$$
\text { Net B / C Ratio }=\frac{\sum_{t=0}^{n} N P V \text { Positif }}{\sum_{t=0}^{n} N P V \text { Negatif }}
$$

Pengambilan keputusan investasi usaha pembenihan dengan kriteria penilaian proyek dengan asumsi apabila Net $\mathrm{B} / \mathrm{C}>1$ berarti investasi layak dilaksanakan (feasible) karena menguntungkan, Net $\mathrm{B} / \mathrm{C}<1$ berarti investasi tidak layak dilaksanakan karena rugi dan Net $\mathrm{B} / \mathrm{C}=1$ berarti proyek berada pada titik impas (break even point).

\section{Internal Rate of Return (IRR)}

IRR merupakan metode untuk menghitung tingkat bunga yang dapat menyamakan antara present value dari semua aliran kas masuk dengan aliran kas keluar dari suatu investasi proyek (Sulisyanto, 2010). Menurut Choliq, dkk (1999) IRR untuk mengetahui 
persentase keuntungan dari suatu proyek tiap-tiap tahun dan merupakan alat ukur kemampuan proyek dalam mengembalikan bunga pinjaman. Analisis IRR menggunakan rumus:

$$
\mathbf{I R R}=\mathbf{i}_{\mathbf{1}}+\frac{N P V^{+}}{N P V^{+}-N P V^{-}}\left(\mathbf{i}_{\mathbf{2}}-\mathbf{i}_{\mathbf{1}}\right)
$$

\section{Keterangan:}

IRR = Nilai Internal Rate of Return

i1 = Faktor discount (tingkat bunga) pertama di mana diperoleh NPV positif

i2 = Faktor discount (tingkat bunga) pertama di mana diperoleh NPV negatif.

Suatu investasi yang diusulkan dinyatakan layak jika IRR lebih besar dari tingkat keuntungan yang dikehendaki. Sebaliknya, jika IRR suatu investasi lebih kecil dari tingkat keuntungan yang dikehendaki maka investasi tersebut dinyatakan tidak layak.

\section{Payback Periods (PBP)}

Payback periods atau tingkat pengembalian investasi adalah salah satu metode dalam menilai kelayakan suatu usaha yang digunakan untuk mengukur periode jangka waktu pengembalian modal. Menurut Choliq, dkk (1999) Payback Periods dapat dicari dengan menggunakan rumus:

$$
\text { Payback Periods }=\frac{\text { Investasi }}{\text { Net Benefit Rata-RataTiapTahun }}
$$

Investasi usaha pembenihan ikan layak dijalankan jika nilai PBP lebih cepat dibandingkan dengan PBP minimum, sebaliknya jika PBP lebih lama dari PBP minimum maka investasi tersebut tidak layak dijalankan karena investasi pembenihan ikan belum mampu menghasilkan pendapatan untuk menutup seluruh biaya yang dikeluarkan pada saat yang telah ditentukan. Husnan dan Suwarno, (1994) menyatakan bahawa semakin cepat modal itu dapat kembali, semakin baik suatu proyek untuk diusahakan karena modal yang kembali dapat dipakai untuk membiayai kegiatan lain.

\section{Analisis Sensitivitas}

Analisis sensitivitas dilakukan untuk meneliti kembali suatu analisis kelayakan proyek, agar dapat melihat pengaruh yang akan terjadi akibat keadaan yang berubahubah atau adanya sesuatu kesalahan dalam dasar-dasar perhitungan biaya dan manfaat. Analisis sensitivitas setiap kemungkinan harus dicoba yang berarti bahwa setiap kali harus dilakukan analisis kembali. Hal ini perlu karena analisis proyek biasanya didasarkan pada proyeksi-proyeksi yang mengandung banyak ketidakpastiaan dan perubahan yang akan terjadi di masa yang akan datang, sehingga dapat mengantisipasi perubahanperubahan tersebut. Pada sektor perikanan, proyek dapat berubah-ubah sebagai akibat dari empat permasalahan utama yaitu perubahan harga jual pokok, keterlambatan pelaksanaan proyek, kenaikan biaya dan perubahan nilai volume produksi.

\section{PEMBAHASAN}

\section{Proyeksi Permintaan Benih Ikan Air Tawar di Kabupaten Kubu Raya}

Produksi perikanan budidaya menurut jenis komoditasnya di Kabupaten Kubu Raya berdasarkan data statistik Dinas Perikanan dan Kelautan Kabupaten Kubu Raya, (2011) tersebut maka permintaan pasar akan kebutuhan benih ikan di Kabupaten Kubu Raya dapat diestimasikan seperti yang disajikan pada Tabel 1. 
Tabel 1. Estimasi Kebutuhan Benih Ikan di Kabupaten Kubu Raya

\begin{tabular}{rlrccrr}
\hline No & $\begin{array}{c}\text { Jenis } \\
\text { Komoditas }\end{array}$ & $\begin{array}{r}\text { Produk } \\
\text { si (ton) }\end{array}$ & $\begin{array}{c}\text { Kelulusan } \\
\text { Hidup (\%) }\end{array}$ & Size & $\begin{array}{c}\text { Populasi } \\
\text { (Ekor) }\end{array}$ & $\begin{array}{c}\text { Estimasi } \\
\text { Kebutuhan } \\
\text { Benis }\end{array}$ \\
\hline 1. & Lele & 255,25 & 50 & 8 & 2.042 .000 & 4.084 .000 \\
2. & Mas & 347,00 & 50 & 4 & 1.388 .000 & 2.776 .000 \\
3. & Nila & 101,08 & 50 & 4 & 404.320 & 808.640 \\
4. & Patin & 19,20 & 50 & 1 & 19.200 & 38.400 \\
\hline & Jumlah & $\mathbf{7 2 2 , 5 3}$ & & & $\mathbf{3 . 8 5 3 . 5 2 0}$ & $\mathbf{7 . 7 0 7 . 0 4 0}$ \\
\hline
\end{tabular}

Sumber: Hasil Analisis Permintaan Benih di Kabupaten Kubu Raya, 2012

Analisis data pada Tabel 1 tersebut dapat disimpulkan bahwa kebutuhan benih ikan untuk budidaya ikan air tawar, yaitu: 1) ikan lele 4.084.000 ekor; 2) ikan nila 2.776.000 ekor; 3) ikan mas 808.640 ekor dan 4) ikan patin 38.400 ekor.

\section{Kapasitas Produksi Usaha Pembenihan Ikan}

Jumlah kolam dan luas masing-masing kolam dalam BBI lokal disajikan pada Tabel 2 berikut ini.

Tabel 2. Jumlah dan Luas Masing-Masing Kolam di BBI Lokal Kabupaten Kubu Raya

\begin{tabular}{clccrr}
\hline No & Macam Kolam & Jumlah & Satuan & Luas $\left(\mathbf{m}^{\mathbf{2}}\right)$ & Jumlah ${ }^{2}$ ) \\
\hline 1. & Kolam induk betina & 6 & Unit & 100 & 600 \\
2. & Kolam induk jantan & 6 & Unit & 100 & 600 \\
3. & Kolam pemijahan & 4 & Unit & 20 & 80 \\
4. & Kolam pendederan I (P I) & 5 & Unit & 250 & 1.250 \\
5. & Kolam pendederan II (P II) & 5 & Unit & 500 & 2.500 \\
6. & Kolam pendederan III (P III) & 5 & Unit & 1.000 & 5.000 \\
7. & Kolam pendederan IV (P IV) & 5 & Unit & 1.500 & 7.500 \\
8. & Kolam pembesaran & 2 & Unit & 100 & 200 \\
9. & Kolam calon induk & 6 & Unit & 500 & 300 \\
10. & Kolam makanan alami & - & Unit & - & - \\
\hline & Jumlah & $\mathbf{4 0}$ & Unit & & $\mathbf{2 0 . 7 3 0}$
\end{tabular}

Sumber: Dinas Perikanan dan Kelautan Kabupaten Kubu Raya, 2010

\section{Proyeksi Produksi Benih Ikan di BBI Lokal Kabupaten Kubu Raya}

Proyeksi produksi benih ikan berdasarkan SNI pembenihan ikan dan studi literature yang berkaiatan dengan pembenihan ikan. Proyeksi produksi benih ikan meliputi: nila, ikan lele dumbo dan mas. Produksi benih ikan tersebut sesuai dengan permintaan jenis ikan pembudidaya di Kabupaten Kubu Raya dan Provinsi Kalimanatan Barat dan disesuaikan dengan sarana dan prsarana BBI lokal Kabupaten Kubu Raya serta standar minimal produksi benih di BBI lokal. Pola produksi benih ikan produksi merupakan metode yang digunakan untuk mengestimasi benih yang akan diproduksi, dari hasil pemijahan ikan. Pola produksi benih ikan sampai pendederan 1 (P1) seperti terlihat dalam Tabel 3 berikut: 
Tabel 3. Pola Produksi Benih Ikan Sampai Pendederan

\begin{tabular}{lccccccccccccccccc}
\hline Bulan & \multicolumn{1}{c}{ I } & \multicolumn{1}{c}{ II } & \multicolumn{1}{c}{ II } & \multicolumn{1}{c}{ III } & \multicolumn{1}{c}{ IV } \\
\hline Minggu & $\mathbf{1}$ & $\mathbf{2}$ & $\mathbf{3}$ & $\mathbf{4}$ & $\mathbf{1}$ & $\mathbf{2}$ & $\mathbf{3}$ & $\mathbf{4}$ & $\mathbf{1}$ & $\mathbf{2}$ & $\mathbf{3}$ & $\mathbf{4}$ & $\mathbf{1}$ & $\mathbf{2}$ & $\mathbf{3}$ & $\mathbf{4}$ \\
KLP & I & LI & II & LII & III & LIII & IV & LIV & I & LI & II & LII & III & LIII & IV & LIV \\
Pi & & & BI & BI & BI & BII & BIII & BIII & BI & BIV & BI & BI & BII & BII & BIII & BIII
\end{tabular}

Sumber: Direktorat Jendral Perikanan Budidaya, 2006

Keterangan: I (Induk Ikan), LI (Larva kelompok induk), B (Benih kelompok induk), KLP (Kelompok induk), dan P1 (Pendederan 1)

\section{Analisis Kelayakan Usaha Pembenihan Ikan}

Kriteria kelayakan investasi yang digunakan adalah NPV, IRR, Net B/C ratio dan Payback Periods. Hasil perhitungan analisa finansial investasi usaha pembenihan ikan di BBI lokal Kabupaten Kubu Raya disajikan pada Tabel 4 berikut ini.

Tabel 4. Hasil Analisa Finansial Investasi Usaha Pembenihan Ikan di BBI Lokal Kabupaten Kubu Raya

\begin{tabular}{clcc}
\hline No & Kriteria Kelayakan Investasi & Hasil nalisis & Keputusan Investasi \\
\hline 1. & Net Presen Value (NPV) & 4.698 .084 & \\
2. & Net Benefit/Cost (Net B/C Ratio) & 1,19 & Investasi layak \\
3. & Internal Rate of Return (IRR) & $16,17 \%$ & dilaksanakan \\
4. & Pay Back Periods (PBP) & 5,1 tahun & \\
\hline
\end{tabular}

Sumber: Hasil analisis, 2012

Berdasarkan Tabel 4 dapat dilihat bahwa hasil analisis usaha pembenihan ikan, yaitu: nilai NPV yang dihasilkan dari investasi pembenihan ikan adalah lebih besar dari nol atau sebesar Rp 4.698.084. Hal ini berarti pengusahaan pembenihan ikan menurut nilai sekarang layak untuk dilakukan atau menguntungkan, karena dapat memberikan tambahan manfaat sebesar $\mathrm{Rp}$ 17.736.295 dalam jangka waktu usaha pembenihan ikan 10 tahun dan nilai Net B/C ratio yang diperoleh adalah lebih besar dari satu yaitu 1,19. $\mathrm{Hal}$ ini berarti setiap satu rupiah biaya yang dikeluarkan pada pengusahaan pembenihan ikan akan memberikan tambahan manfaat untuk pendapatan bersih sekarang sebesar Rp 1,9 dengan jangka waktu pengembalian modal selama 10 tahun atau keuntungan 1,10 kali lipat dari modal dengan demikian investasi pembenihan ikan ini layak untuk dilaksanakan.

Nilai Internal Rate of Return (IRR) yang diperoleh dari investasi usaha pembenihan ikan lebih besar dari DF dari suku bunga kredit usaha 14\%, yaitu sebesar $16,17 \%$. Sehingga jika dilihat dari kriteria kelayakan finansial IRR, investasi usaha pembenihan ikan ini layak utuk dijalankan dan akan dapat mengembalikan kredit dengan bunga yang dibebankannya dan berdasarkan hasil analisis Payback periods, maka pengembalian investasi yang dikeluarkan pada investasi pembenihan ikan, dapat dikembalikan pada saat usaha telah berjalan selama 5 tahun 1 bulan dari 10 tahun umur usaha.

Analisis sensitivitas bertujuan untuk melihat sampai seberapa besar perubahan yang terjadi pada komponen manfaat dan biaya dari hasil analisis kelayakan menghasilkan nilai $\mathrm{NPV}=0$, Net $\mathrm{B} / \mathrm{C}$ ratio $=1$, dan IRR $=$ tingkat discount rate $14 \%$. Analisis sensitivitas dilakukan untuk meneliti kembali suatu analisis kelayakan proyek, agar dapat melihat pengaruh yang akan terjadi akibat keadaan yang berubah-ubah atau 
adanya sesuatu kesalahan dalam dasar-dasar perhitungan biaya manfaat. Hal ini perlu karena analisis proyek biasanya didasarkan pada proyeksi-proyeksi yang mengandung banyak ketidakpastiaan dan perubahan yang akan terjadi di masa yang akan datang. Hasil perhitungan analisa sensitivitas tersebut disajikan apada Table 5 berikut ini.

Tabel 5. Hasil Analisa Sensitivitas Investasi Usaha Pembenihan Ikan di BBI Lokal Kabupaten Kubu Raya

\begin{tabular}{clrc}
\hline Skenario Perubahan & Analisis Profitabilitas & Hasil nalisis & Keputusan Investasi \\
\hline & Net Presen Value (NPV) & $4,575,511$ & \\
Kenaikan Biaya & Net Benefit/Cost (Net B/C) & 1,10 & Investasi layak \\
Produksi 7,62\% & Internal Rate of Return (IRR) & $16,11 \%$ & dilaksanakan \\
& Pay Back Periods (PBP) & 5,6 tahun & \\
\hline
\end{tabular}

Sumber: Hasil analisis, 2012

Berdasarkan Tabel 5 dapat dilihat bahwa hasil analisis usaha pembenihan ikan, yaitu: 1) nilai NPV yang dihasilkan dari investasi pembenihan ikan adalah lebih besar dari nol atau sebesar Rp 4.575.511; 2) nilai Net B/C ratio yang diperoleh adalah lebih besar dari satu yaitu 1,10, artinya keuntungan 1,10 kali lipat dari modal; 3) nilai IRR yang diperoleh dari investasi usaha pembenihan ikan lebih besar dari DF dari suku bunga kredit usaha $14 \%$, yaitu sebesar $16,17 \%$. Hasil analisis PBP maka pengembalian investasi yang dikeluarkan pada investasi pembenihan ikan, dapat dikembalikan pada saat usaha telah berjalan selama 5 tahun 6 bulan dari 10 tahun umur usaha pembenihan ikan. Meskipun terjadi kenaikan biaya operasional produksi pembenihan ikan meliputi: pakan, pupuk, kapur dan obat-obatan sampai 7,62\% investasi usaha pembenihan ikan di BBI lokal Kabupaten Kubu Raya masih layak diusahakan.

\section{KESIMPULAN DAN SARAN}

\section{Kesimpulan}

Berdasarkan Analisis kelayakan investasi pembenihan ikan di BBI lokal Kabupaten Kubu Raya dapat disimpulkan:

1. Permintaan benih ikan sebagai input pembudidaya di Kabupaten Kubu Raya adalah lele dumbo 4.084 .000 ekor, nila 2.776.000 ekor dan mas 808.640 ekor, sedangkan kebutuhan benih ikan di Kalimantan Barat benih lele 36,106,560 ekor, nila 20,913,680 ekor, mas 20,482,880 ekor.

2. Perencanaan usaha pembenihan ikan di BBI lokal Kabupaten Kubu Raya disesuaikan sarana dan prasaran yang dimiliki meliputi: ikan lele, nila dan mas dengan kapasitas produksi benih lele 2.288.000 ekor, nila 1.884.000 dan mas 1.055.000 ekor dan dapat dipasarkan ke pembudidaya ikan di Kabupaten Kubu Raya.

3. Hasil analisis kelayakan investasi usaha pembenihan ikan di BBI lokal Kabupaten Kubu Raya meliputi usaha pembenihan ikan lele, nila dan mas maka hasil analisis NPV $=4.698 .084$, berarti NPV $>0$, Net B/C 1,19 maka Net B/C > 0, IRR 16, 17\% lebih besar dari DF 14\%, dan Payback Periods (PBP) 5 tahun 1 bulan lebih pendek dari umur proyek 10 tahun.

4. Analisa sensivitas dengan asumsi jika.terjadi kenaikan biaya produksi (pakan, pupuk, kapur dan obat-obatan) sebesar 7,62\% nilai profitabilitas NPV $=4.575 .511$, Net B/C 1,10, IRR 16, 11\%, dan Payback Periods (PBP) 5 tahun 6 bulan itu artinya NPV> 0 (bernilai positif), Net B/C > 0, IRR > DF 14\% dan PBP lebih pendek dari umur proyek 10 tahun 


\section{Saran}

Investasi usaha pembenihan ikan agar hasil produksi benih sesuai dengan perencanaan maka Manajer pengendali mutu (MPM) diperlukan di unit pembenihan ikan untuk memastikan proses produksi sesuai dengan SNI proses produksi secara konsisten menerapakan konsep cara pembenihan ikan yang baik dan benar (CPIB) dengan penerapan Standar Nasional Indonesia (SNI) baik induk yang digunakan, proses produksi sehingga menghasilkan benih sesuai SNI.

\section{DAFTAR PUSTAKA}

Badan Pusat Statistik (BPS), 2010. Kabupaten Kubu Raya Dalam Angka 2010. Kabupaten Kubu Raya.

Direktur Jenderal Perikanan Budidaya, 2006. Petunjuk Teknis Balai Benih Ikan (BBI) dan Balai Benih Ikan Sentral (BBIS). Direktorat Perbenihan, Direktorat Jendral Perikanan Budidaya. Departemen Kelautan dan Perikanan. Jakarta

Mudjiutami. E, 2011. Peranan BBAT Mandiangin Dalam Menunjang Ketersediaan Benih dan Induk Unggul Ikan Air Tawar. Disampaikan pada Temu Teknis Petugas BBI kabupaten/Kota se-Kalimantan Barat. Balai Budidaya Air Tawar Mandiangin Direktorat Jendral Perikanan Budidaya Kementrian Kelautan dan Perikanan Kalimantan Selatan.

Trenggonowati, 2009. Metode Penelitian Ekonomi dan Bisnis. BPFE. Anggota IKAPI. Yogyakarta.

Triton. 2005. Manajemen Investasi Proyek Analisis dan Strategi. Tugu Publiser. Yogyakarta. 